\title{
Perceived stigma and school attendance among children and adolescents with epilepsy in South Western Uganda
}

\author{
Joseph Kirabira ${ }^{1}$, Ben Jimmy Forry ${ }^{1}$, Robyn Fallen ${ }^{2}$, Bernard Sserwanga ${ }^{1}$, Godfrey Zari Rukundo ${ }^{1}$
}

1. Department of Psychiatry, Mbarara University of Science and Technology (MUST), P.O. Box 1410, Mbarara, Uganda.

2. Department of Psychiatry and Behavioural Neurosciences, McMaster University, Kitchener Ontario, Canada.

\section{Emails:}

2015mmed050@stud.must.ac.ug; bforry@must.ac.ug; robyn.fallen@medportal.ca; ssbernard101@hotmail.com; Godfrey Zari Rukundo; grukundo@must.ac.ug

\begin{abstract}
Background: Epilepsy is a neurological disorder that has a high worldwide prevalence with eighty percent of the global burden being in low and middle-income countries. There is a high level of perceived stigma among children and adolescents with epilepsy, which has severe debilitating effects and affects school attendance.

Objective: To assess the effect of perceived stigma on school attendance patterns among children and adolescents with epilepsy. Methods: We conducted a cross sectional study among 191 children and adolescents aged from 6-18 years with epilepsy at one large semi-urban hospital and a small rural health center in SouthWestern Uganda. Epilepsy-related perceived stigma was measured using the adapted Kilifi Stigma Scale of Epilepsy and school attendance patterns were assessed using a piloted investigator-designed questionnaire.

Results: Children with high-perceived stigma were more likely to have never attended school (13.8\%) or started school late (average age 5.7 years) compared to those with low-perceived stigma (average age 4.9 years). Additionally, those with high epilepsy-related perceived stigma repeated classes 2.5 times more compared to those with low-perceived stigma.

Conclusion: These preliminary findings suggest correlation between high-perceived stigma and disrupted school attendance patterns among children and adolescents with epilepsy, hence the need to address this social challenge.

Keywords: Epilepsy, perceived stigma, school attendance, children, adolescents, Uganda.

DOI: https://dx.doi.org/10.4314/ahs.v20i1.43

Cite as: Kirabira J, Forry BJ, Fallen R, Sserwanga B, Rukundo GZ. Perceived stigma and school attendance among children and adolescents with epilepsy in South Western Uganda. Afri Health Sci. 2020;20(1):376-82. https:/ / dx.doi.org/ 10.4314/ ahs.v20i1.43
\end{abstract}

\section{Corresponding author: \\ Joseph Kirabira, \\ Department of Psychiatry, \\ Mbarara University of Science \\ and Technology (MUST), \\ P.O. Box 1410, Mbarara, Uganda \\ Tel: +256703032703 \\ 2015mmed050@stud.must.ac.ug}

\section{Background Introduction}

Epilepsy is a brain disorder characterized by at least two unprovoked seizures more than 24 hours apart or one unprovoked seizure when the risk for another is known to be high $(>60 \%)$, reflex seizures and seizures that are part of an epilepsy syndrome ${ }^{1}$. It is highly prevalent globally but most of the affected individuals are from low and middle income countries ${ }^{2}$. In 1997, more than $2 \%$ of 
children and adolescents in southwestern Uganda lived with epilepsy ${ }^{3,4}$. In Iganga-Mayuge (Eastern Uganda), 14.8 per 1000 persons lived with active epilepsy by $2009^{5}$. In 2015, epilepsy accounted for 53\% of all childhood disorders at Mbarara Regional Referral Hospital psychiatry department ${ }^{6}$. In SouthWestern Uganda, control measures against epilepsy include community sensitization; screening; diagnosis and management through community out-reach projects as part of mental-health outreach programs ${ }^{7}$. However, some people in the region also still use some local herbs for management ${ }^{3}$. Epilepsy is characterized by high levels of stigma among the sufferers in low, middle and high-income countries ${ }^{8}$, with perceived stigma (PS) being the most debilitating. Prevalence of PS of epilepsy has wide geographical variations ranging from $17.6 \%$ in Korea $^{10}$ to $71.6 \%$ in Ethiopia ${ }^{11}$. PS negatively affects quality of life and self-esteem ${ }^{9}$ leading to reduced social interaction and performance ${ }^{12}$. Among children and adolescents with epilepsy (CAWE), PS is likely to lead to avoidance of social interactions with peers and adults leading to school avoidance. This can also result in irregular school attendance patterns and subsequent academic underachievement ${ }^{13,14}$. Several studies have established that children with epilepsy start attending school late, miss more school days ${ }^{15}$, repeat more classes and many don't progress beyond their entry classes or never attend school at all ${ }^{3}$. It is not clear whether epilepsy or its effects (such as stigma) are responsible for these experiences.

Childhood and adolescence are key transitional stages when significant learning and development take place, laying the foundation for the individual's life course. Consistent school attendance for CAWE optimizes educational opportunities, which can increase the likelihood their future productivity (including rates of school completion, pursuing higher education, and career opportunities) comparable to peers without epilepsy. However, few studies have been conducted to assess the effect of PS on school attendance patterns among children and adolescents with epilepsy which, when addressed, can lead to better school performance of those affected.

Therefore, we carried out a cross sectional study among CAWE attending Mbarara Regional Referral hospital (MRRH) and Rubindi Health Center III (RHC) in southwestern Uganda to assess the relationship between epilepsy-related perceived stigma and school attendance patterns.

We hypothesized that epilepsy-related perceived stigma affects the school attendance patterns of children and adolescents with epilepsy.

\section{Methods}

We carried out the study at MRRH Psychiatry out-patient clinic and RHC mental health outreach clinic among CAWE aged from 6 to 18 years attending these two clinics. We used consecutive sampling and recruited 191 children and adolescents calculated using Openep ${ }^{16}$ online software with a power of $80 \%$ and $5 \%$ level of significance. We only included those children whose diagnosis of epilepsy was made by a specially trained psychiatry resident, psychiatrist or neurologist, had been on epilepsy treatment for at least three months and could meaningfully respond to the research questions. We excluded those with medical emergencies such as status epilepticus from the study. We recruited participants consecutively at both study sites until we reached the required sample size.

MRRH is a large semi-urban hospital offering general and specialized medical services to people in SouthWestern Uganda through various inpatient and outpatient departments or clinics. It acts as the regional referral center as well as a training center for medical students from several medical school including Mbarara University of Science and Technology (MUST). At this hospital, residents in the psychiatry, pediatrics and internal medicine (neurology) as well as psychiatrists and neurologists manage people with epilepsy. At the psychiatry department, this is done at an inpatient, outpatient and outreach basis. Epilepsy accounts for more than half of all childhood disorders in the psychiatry department ${ }^{6}$. One of the outreach sites is RHC, which is a smaller health center in rural SouthWestern Uganda offering general medical services to people from Rubindi and nearby villages. A mental health outreach team from MRRH Psychiatry department offers treatment of people with epilepsy and mental illness at this health center one day per month. This outreach service program has been sustained through community involvement whereby patients and their relatives contribute to the cost of anti-epileptic drugs (AEDs) and voluntary mental health team offers free medical care. The epilepsy care service at both sites involves diagnostic clarification and prescription of AEDs as well as counseling and psychoeducation for the patients and their caretakers about the condition. 
Research assistants underwent a five-day training about the use of all research instruments as well as ethical conduct of research. They identified potential participants by review of their medical records on a clinic day; all that met the pre-defined eligibility criteria were offered enrollment in the study. We obtained written informed consent from participants aged eighteen years and from adult caretakers of children less than eighteen years. We also obtained assent from children aged eight to seventeen years. The trained research assistants administered a piloted electronic questionnaire using tablets to assess school attendance patterns among the participants. We measured epilepsy related perceived stigma using the adapted Kilifi Stigma Scale of Epilepsy (KSSE). The KSSE is a fifteen-item Likert score scale with good psychometric properties that was developed and validated in Kilifi, Kenya for use in the measurement of epilepsy-related perceived stigma among both children and adults17. Each item has responses of Never $=0$, sometimes $=1$, Often $=2$ and very often $=3$ and high-perceived stigma is a total score above the 66th percentile17, 18. We translated all research tools from English into Runyankore/ Rukiga (local dialect) to cater for participants who could not understand English well.

We analyzed and tested for normality of data using STATA version 13 software. High-perceived stigma was considered as a total score greater than the $66^{\text {th }}$ percentile on the KSSE, whereas low perceived stigma was a score equal or les than the 66th percentile. School attendance patterns among the study participants were analyzed using proportions considering $5 \%$ level of statistical significance and $95 \%$ confidence interval.

We first talked to respondents about the sensitivity of some questions and informed them that they could choose to answer or not to respond if they found the questions difficult. We conducted the interviews in a private room that had only the investigator, participant and where necessary the caretaker. We ensured respondents' confidentiality and integrity throughout data collection. We gave participants unique identification numbers for the purpose of this study strictly and their names, signatures, and those of their relatives were not included in the final report.

\section{Results}

We recruited 191 children with epilepsy of which 114 were from Mbarara Regional Referral Hospital psychiatry department and 77 were from Rubindi Health Center III. The average age of participants was 14.9 years (standard deviation (S.D) $=3.5$ ) (see table 1 for details). Of the total children surveyed, $7.3 \%$ had never attended school. Of those who had ever attended school, $50.3 \%$ had left before completion with $82.2 \%$ of these having left at primary level, $16.1 \%$ at secondary level and only $1 \%$ completed tertiary level training. Of those who were still in school, $61.4 \%$ were in primary, $34.1 \%$ in secondary and only 4.5 $\%$ in tertiary institutions. Additional information about the distribution of socio-demographic factors was can be found here; doi: 10.1016/j.seizure.2018.03.008 
Table 1. Distribution of socio-demographic factors among CAWE $(n=191)$

\begin{tabular}{|c|c|c|c|}
\hline Variable & $\begin{array}{l}\text { Children who have ever attended } \\
\text { school }(n=177)\end{array}$ & $\begin{array}{l}\text { Children who have } \\
\text { never attended school } \\
(n=14)\end{array}$ & $\begin{array}{l}p- \\
\text { value }\end{array}$ \\
\hline $\begin{array}{l}\text { Average } \\
\text { (years) }\end{array}$ & $15.1(S . D=3.4)$ & $12.6(S . D=3.9)$ & 0.017 \\
\hline Sex & & & 0.167 \\
\hline Male & 106 (90.6\%) & 11 & \\
\hline Female & 71 (95.9\%) & 3 & \\
\hline Residence & & & 0.142 \\
\hline Semi urban & $43(97.7 \%)$ & 1 & \\
\hline Rural & $134(91.2 \%)$ & 13 & \\
\hline Care giver & & & 0.806 \\
\hline Mother & 87 (91.6\%) & 8 & \\
\hline Father & 55 (93.2\%) & 4 & \\
\hline Sibling & $19(90.5 \%)$ & 2 & \\
\hline Others & $16(100 \%)$ & Nil & \\
\hline Tribe & & & 0.855 \\
\hline Munyankore & 136 (91.9\%) & 12 & \\
\hline Others & 41 (97.3\%) & 2 & \\
\hline
\end{tabular}

The number of children and adolescents having high-perceived stigma of epilepsy who have never attended school was 3.5 times higher than that of those who have epilepsy but experiencing low perceived stigma (table 2). Among those who ever attended school $(n=177)$, the average age of starting school was 1.2 times higher among children and adolescents experiencing high-perceived stigma compared to those with low perceived stigma. Additionally, the number of children and adolescents with epilepsy having high-perceived stigma that started school after 5 years of age was almost twice as high (table 2). The number of times of repeating classes was 2.5 times higher among participants with epilepsy experiencing high level of perceived stigma than those with epilepsy but experiencing low level of perceived stigma (table 2). The percentage of children with epilepsy having high-perceived stigma that left school was higher $(60.7 \%)$ compared to that of those having low perceived stigma (45.5\%), though this was not statistically significant. In addition, the number of school days missed was higher among children and adolescents having high perceived stigma (7.2 days per term) than that of those with low perceived stigma ( 6 days per term), though this was also not statistically significant

Table 2. School attendance patterns among CAWE experiencing high-perceived stigma and those experiencing low perceived stigma.

\section{School attendance pattern}

Have never attended school

Average age of starting school (in years)

Starting school at age above 5 years

Average number of days missed in a term

Currently attending school

Average number of times of repeating classes

\section{* Standard deviation}

$\begin{array}{lll}\begin{array}{l}\text { children with high } \\ \text { perceived stigma }\end{array} & \begin{array}{l}\text { children with low } \\ \text { perceived stigma }\end{array} & \text { P value } \\ 9(13.8 \%) ; n=65 & 5(4.0 \%) ; n=126 & \mathbf{0 . 0 1 3} \\ 5.7(2.4)^{*} & 4.9(1.9)^{*} & \mathbf{0 . 0 2 1} \\ 28(43.1 \%) ; n=56 & 25(22.3 \%) ; n=121 & \mathbf{0 . 0 0 4} \\ 7.2(16.8)^{*} & 6(16.7)^{*} & 0.764 \\ 22(32.9 \%) ; n=56 & 66(54.5 \%) ; n=121 & 0.059 \\ 2.13(1.4)^{*} & 0.86(1.1)^{*} & \mathbf{0 . 0 0 1}\end{array}$

African Health Sciences Vol 20 Issue 1, March, 2020 


\section{Discussion}

This study was conducted to assess the effect of perceived stigma (PS) of epilepsy on the school attendance among CAWE, in South Western Uganda. We found that children with epilepsy having high PS had poorer school attendance patterns compared to those that have low PS. Children having high-perceived stigma were more likely never to attend school or start at an older age (more than 5 years of age). This may be due to the fear of how they will be treated by other children and teachers at school. Additionally, community misconceptions about epilepsy such as fear of this condition being contagious could probably make the children feel stigmatized hence avoiding school. This is in line with previous findings in the same area, which indicated that about $43.2 \%$ children of school going age were not attending school ${ }^{3}$. However, our study went further to assess the role of epilepsy-related PS on this reported poor school attendance. Children experiencing high-perceived stigma were found to repeat classes more times (2.5 times) compared to their counterparts experiencing low-perceived stigma. These findings are in line with findings from several studies, which have indicated that children with epilepsy have poorer school attendance ${ }^{15,19-21}$. A study by Duggan indicated that most of the children with epilepsy in southwestern Uganda never progress beyond their class of entry3. However, most of these studies did not assess whether perceived stigma of epilepsy contributes to the poor school attendance of those children. These study findings suggest an association between high-perceived stigma of epilepsy and poor school attendance patterns among CAWE.

These findings may also explain why children with epilepsy have poor academic achievement ${ }^{22,23}$, as well as overall academic underachievement $\mathrm{t}^{24,25}$ as reported by existing studies ${ }^{26,27}$. Similar to many resource-limited settings, there are no special schools for children with epilepsy in SouthWestern Uganda. As such, these children attend general schools and there are no formal in-school supports to help them adjust to the academic environment or to ensure the teachers and other children have factual knowledge about epilepsy. Compounding these challenges, there are high poverty levels, very low availability of anti-seizure medicines and limited access to epilepsy care, which predispose the children to poor seizure control. Consequently, these children are vulnerable to having several seizure attacks while at school, which affects their self-image, self-esteem and can contribute to them feeling insecure and stigmatized, hence leaving school. Those who managed to stay in school may have to endure discrimination and maltreatment from fellow children and sometimes teachers who are not well informed or sensitized to the realities of living with epilepsy. These factors can contribute to children missing more school days and school activities, leading to poorer performance and hence less academic progress. Although this current study highlights the relationship between perceived stigma and school attendance, the factors contributing to this connection are likely complex and multifactorial. It can beypothesized that perceived stigma is a key factor in explaining the poor school attendance patterns among children with epilepsy, which results in lower academic achievement. This puts these youths at risk of future inequalities socially, economically and in terms of employment opportunities due to the educational gaps and risks perpetuating a vicious cycle of poverty.

\section{Conclusion}

These are preliminary findings suggesting that epilepsy related perceived stigma among children of school going age negatively affects their school attendance patterns, which can have negative impacts on their future. There is dire need for conducting studies to further explore the direct association between epilepsy related perceived stigma and poor school attendance especially in low resource settings. Understanding this association will help in designing psychosocial interventions to reduce this stigma in order to improve the school attendance of children with epilepsy, with a goal of improving academic performance and achievement for this vulnerable population. There is also need to carry out larger prospective surveys in schools to assess how the academic environment influences the perception of stigma by children with epilepsy. Limitation: This was an institution-based study that did not explore some other possible factors that can influence of school attendance.

\section{Acknowledgements}

- $\quad$ MURTI for organizing multiple research trainings, which equipped us with the required skill to conduct this study and more others.

- Prof. Sheila Harms of McMaster University and Honorary Lecturer at MUST and Dr. Alice Lam of Harvard University for the continuous mentorship and guidance. 
the cooperation during the data collection process.

- McMaster University Department of Psychiatry for the support given to the MUST psychiatry department in terms of teaching and resources.

Fellow residents in the department of psychiatry at MUST including Drs Lucas Anyayo, Achille Bapolisi, and Claire Kesande for the peer support

\section{Declaration}

Ethics approval and consent to participate

Ethical approval to conduct the study was obtained from MUST Research Ethics Committee

\section{Competing interests}

"The authors declare that they have no competing interests"

\section{Funding}

Kayanja Fellowship of Mbarara University of Science and Technology as a routine requirement for completing a postgraduate program for the fellows funded the study. The funder had no role in the design of the study and collection, analysis, and interpretation of data and in writing the manuscript.

\section{Abbreviations}

CAWE: Children and adolescents with epilepsy

MRRH: Mbarara Regional Referral Hospital

MUST: Mbarara University of Science and Technology

RHC: Rubindi Health Center III

PS: Perceived Stigma

\section{References}

1. R. S. Fisher et al., "ILAE Official Report: A practical clinical definition of epilepsy," Epilepsia, vol. 55, no. 4, pp. 475-482, 2014.

2. WHO, "WHO | Epilepsy Fact sheet," WHO, 2017. Online. Available: http://www.who.int/mediacentre/ factsheets/fs999/en/.

3. M. B. Duggan, "Epilepsy and its effects on children and families in rural Uganda.," Afr. Health Sci., vol. 13, no. 3, pp. 613-23, 2013.

4. M. B. Duggan, "Epilepsy in rural Ugandan children: Seizure pattern, age of onset and associated findings," Afr. Health Sci., vol. 10, no. 3, pp. 218-225, 2010.

5. A. K. Ngugi et al., "Prevalence of active convulsive epilepsy in sub-Saharan Africa and associated risk factors:
Cross-sectional and case-control studies," Lancet Neurol., vol. 12, no. 3, pp. 253-263, 2013.

6. O. Joseph, Z. R. Godfrey, and A. Hall, "Diagnosis and treatment of mental health problems among children and adolescents at Mbarara regional referral hospital, south western Uganda," Manuscr. under Rev., no. Under review, 2018.

7. E. Byaruhanga, E. Cantor-Graae, S. Maling, and J. Kabakyenga, "Pioneering work in mental health outreaches in rural, SouthWestern Uganda," Intervention, 2008.

8. H. M. de Boer, M. Mula, and J. W. Sander, "The global burden and stigma of epilepsy," Epilepsy and Behavior, vol. 12, no. 4. pp. 540-546, 2008.

9. M. Mula and J. W. Sander, "Psychosocial aspects of epilepsy: a wider approach,' Br. J. Psychiatry Open, vol. 2, no. 4, pp. 270-274, 2016.

10. G. H. Lee et al., "Factors contributing to the development of perceived stigma in people with newly diagnosed epilepsy: A one-year longitudinal study," Epilepsy Behav., vol. 54, pp. 1-6, 2016.

11. B. B. Bifftu, B. A. Dachew, and B. T. Tiruneh, "Perceived stigma and associated factors among people with epilepsy at Gondar university hospital, northwest Ethiopia: A cross-sectional institution based study," Afr. Health Sci., vol. 15, no. 4, pp. 1211-1219, 2015.

12. D. P. McLaughlin, N. A. Pachana, and K. Mcfarland, "Stigma, seizure frequency and quality of life: The impact of epilepsy in late adulthood," Seizure, vol. 17, no. 3, pp. 281-287, 2008.

13. R. C. Ibekwe, N. C. Ojinnaka, and S. O. Iloeje, "Factors influencing the academic performance of school children with epilepsy," J. Trop. Pediatr., vol. 53, no. 5, pp. 338-343, 2007.

14. S. W. Wo, L. C. Ong, W. Y. Low, and P. S. M. Lai, “The impact of epilepsy on academic achievement in children with normal intelligence and without major comorbidities: A systematic review," Epilepsy Research, vol. 136. pp. 35-45, 2017.

15. B. V. K. Aguiar, M. M. Guerreiro, D. McBrian, and M. A. Montenegro, "Seizure impact on the school attendance in children with epilepsy," Seizure, vol. 16, no. 8, pp. 698-702, 2007.

16. K. M. Sullivan, A. G. Dean, and R. A. Mir, "Sample Size for Cross-Sectional, Cohort, \& Randomized Clinical Trial Studies." OpenEpi: Open Source Statistics for Public Health, Emory University, 2007.

17. C. K. Mbuba, A. Abubakar, P. Odermatt, C. R. Newton, and J. A. Carter, "Development and validation of 
the Kilifi Stigma Scale for Epilepsy in Kenya,' Epilepsy Behav., vol. 24, no. 1, pp. 81-85, 2012.

18. J. Kirabira, M. Nakawuki, R. Fallen, and G. Zari, "Perceived stigma and associated factors among children and adolescents with epilepsy in south western Uganda : A cross sectional study," Seizure Eur. J. Epilepsy, vol. 57, pp. 50-55, 2018.

19. P. N. Pastor, C. A. Reuben, R. Kobau, S. L. Helmers, and S. Lukacs, "Functional difficulties and school limitations of children with epilepsy: Findings from the 20092010 National Survey of Children with Special Health Care Needs," Disabil. Health J., vol. 8, no. 2, pp. 231-239, 2015.

20. D. B. Ali, M. Tomek, and D. R. Lisk, "The effects of epilepsy on child education in Sierra Leone," Epilepsy Behav., vol. 37, pp. 236-240, 2014.

21. D. Mushi, K. Burton, C. Mtuya, J. K. Gona, R. Walker, and C. R. J. C. Newton, "Perceptions, social life, treatment and education gap of Tanzanian children with epilepsy: A community-based study," Epilepsy Behav., vol. 23, no. 3, pp. 224-229, 2012.
22. C. Reilly and B. G. R. Neville, "Academic achievement in children with epilepsy: A review," Epilepsy Res., vol. 97, no. 1-2, pp. 112-123, 2011.

23. K. P. Vinayan, "Epilepsy, antiepileptic drugs and educational problems.," Indian Pediatr., vol. 43, pp. 786-794, 2006.

24. A. P. Aldenkamp, B. Weber, W. C. G. Overweg-Plandsoen, R. Reijs, and S. van Mil, "Educational underachievement in children with epilepsy: a model to predict the effects of epilepsy on educational achievement.," J. Child Neurol., vol. 20, no. 3, pp. 175-80, 2005.

25. D. Almane et al., "Brief clinical screening for academic underachievement in new-onset childhood epilepsy: Utility and longitudinal results," Epilepsy Behav., vol. 43, pp. 117-121, 2015.

26. H. Singh, S. Aneja, K. E. S. Unni, A. Seth, and V. Kumar, "A study of educational underachievement in Indian children with epilepsy.", Brain Dev., vol. 34, no. 6, pp. 504-10, 2012.

27. A. O. Adewuya, S. B. A. Oseni, and J. A. O. Okeniyi, "School performance of Nigerian adolescents with epilepsy," Epilepsia, vol. 47, no. 2, pp. 415-420, 2006. 